\title{
Healthcare Customer Relationship Management: Marketing Process Deliverable Approach
}

\author{
Roxana MARCU*, Dan POPESCU \\ Faculty of Automatic Control and Computers, University POLITEHNICA of Bucharest, \\ 313 Splaiul Independentei, Sector 6, Bucharest, 060042, Romania \\ roxana.marcu@stud.acs.upb.ro (*Correspondingauthor),dan.popescu@upb.ro
}

\begin{abstract}
Healthcare industry represents one of the most important contexts for implementing the development strategies of software companies. This is due to complexity of medical processes and recent regulations that force healthcare providers to implement information systems. Due to the complexity of healthcare authors identified a need of visualizing medical processes as a prerequisite for implementing healthcare information systems. The proposed solution presents a process deliverable diagram (PPD) as the main approach to exemplifying healthcare industry. An example of a standard marketing segmentation and campaign execution mapped on a disease prevention program for cancer screening is exemplified in this paper by means of PPD.
\end{abstract}

Keywords: CRM, Marketing, Healthcare, Process-deliverable diagram.

\section{Introduction}

A healthcare information system refers to a collection of medical, economic and information components implemented in a unique, fully integrated architecture with the purpose of delivering high quality services.

Healthcare is becoming one of the most significant sectors of the economy in many countries due to the need of increasing the average life expectancy (Islam et al., 2018). The aim of such a system is to improve quality of medical services, maintain customer loyalty, increase profit for the providers, control costs for patients and protect their privacy through the implementation of information systems in the medical sector. Average life expectancy has been significantly increased in the last century due to healthcare quality and disease prevention according to statistics published by World Health Organization in 2015. The results have been published in a study that indicates the lowest overall life expectancies in countries that do not have any national disease prevention program implemented (WHO, 2016).

On the other hand, healthcare services have undergone a significant improvement on the market due to the implementation of more and more legal and economic regulations. The purpose of the healthcare industry is to increase the financial revenues by attracting new patients and offering them quality healthcare services, ensuring their satisfaction and increasing the probability of them recommending a certain health facility to others.
The purpose of this paper is to present a use case of marketing processes in healthcare domain with the aim of increasing financial revenues for the healthcare providers while implementing a strong disease prevention program across their patients. The remainder of this paper is structured as follows. The background of healthcare literature and the existing studies are presented in Section 2. Section 3 sets forth a standard marketing process that can be implement in the healthcare industry making use of any Customer Relationship Management (CRM) system including a marketing solution (segmentation and campaign management). This process is presented by means of PDD. Section 4 concludes the article with a discussion of the limitations of this research, followed by conclusion and directions for future research.

\section{Background and Related Work}

The aim of the CRM system seen as an integrated approach is to identify, acquire and retain customers as an umbrella concept encompassing three main components: sales, services and marketing. Major key players on the healthcare CRM market are multinational software corporations creating enterprise software like Salesforce.com, SAP, Oracle, Microsoft and IBM which control more than $22 \%$ of the market.

Healthcare CRM market is estimated to grow at a robust Compound Annual Growth Rate (CAGR) 
of $14.6 \%$ reaching 17.4 billion USD by 2023 , up from 8.8 billion USD in 2018 according to a complex market analysis report published by (ReportsnReports, 2018).

In (Baashar et al., 2016) authors present a review of the existing academic studies in the area of implementation of CRM systems in healthcare organizations which were published between 2005 and 2015. Based on this review, there is a significant lack of research in healthcare CRM. Literature only presents success rates that could be achieved and it does not discuss how healthcare organizations could achieve such an implementation.

A study conducted over a period of 22 months (January 2015 - October 2016) for 126 new patients of a healthcare provider is presented in (Radu et al., 2017). The study emphasizes the need of the marketing processes as part of CRM system implementation for the promotion of medical care services. According to this study all new patients that have been attracted through marketing promotions via social channels remained patients of the respective healthcare provider. New achieved patients increase the financial revenue of the provider and in parallel improve quality of the services delivered to the patient.

Healthcare industry seen as a business, provides medical services to the people while considering them to an equal extent, customers and beneficiaries of medical treatment (Torpie, 2016). Healthcare focuses on two main directions: identifying and satisfying the patients' needs in order to gain new patients and maintain a strong relationship with the existing ones.

In (Jones et al., 2005) a complex study on market segmentation into select target groups for sun protection campaigns is presented and analysed from the perspective of two directions of healthcare: acceptability of stakeholders and health impact. Based on both scientific papers and conducted researches authors managed to identify the age of the targeted consumers as the most significant variable. Various target groups segmented by age are evaluated in terms of health impact, research, stakeholders and accessibility with the aim of rate potential markets. The study is concluded with a need of developing a market segmentation framework that can be used in order to translate the medical information into meaningful technical variables that can be implemented via an information system.

Researches identified the need of healthcare providers for a structured framework for analysing and studying their processes and designated systems. Literature presents multiple personalized, non-standardized solutions of frameworks that could be employed in order to achieve this (Ceresoli \& Kuhl, 2018).

Paper (Blijleven et al., 2016) presents a metamodelling technique used to model healthcare processes using PPD for analyze, design and adapt healthcare processes. This research proves that PPD can be successfully adopted from the engineering to research domain and in particularly for healthcare.

Based on the researches carried out in this domain, authors concluded that according to the economic studies there is a need for CRM implementation for healthcare providers. Unfortunately, there is a lack of research in the area of healthcare processes that could be implemented in order to achieve benefits for patients and healthcare providers.

\section{The Proposed Solution}

The proposed solution is considering the marketing processes as a standalone system and pointing out, when it is the case, the integration of the marketing system with other information systems. Main marketing functionalities are taken into consideration and mapped onto the needs of healthcare service providers: unified profile along with legal regulations, segmentation, campaign execution and campaign performance.

Integration architecture of multiple information systems has been presented by authors in (Marcu $\&$ Popescu, 2015) and it is not part of this paper.

Based on the experience of one of the authors as solution architect in implementing marketing information system the following step-by-step methodology is proposed: 
1. Review literature on medical segmentation in order to identify already used segmentation

2. Segmentation variables;

3. Review existing case studies;

4. Conduct interviews with medical specialists in order to identify medical information that could be translated into a campaign;

5. Create segmentation, clustering similar populations into target groups;

6. Create a matrix that collects all achieved information (target groups and impact variables);

7. Create a campaign automation running on the identified target groups in previous step;

8. Monitor campaign results and present feedback with medical specialist and medical provider representative.

Business methodology is to be followed by the visualization and understanding of medical processes from the perspective of information system implementations. This paper proposes a
Process Deliverable Diagram (PDD) as the main tool for visualization and analysing. In the next section, the standard PDD method is employed for describing the interdependencies of the business process model and the data flows. PDD can be successfully applied in healthcare as well as in any other industry as it is just a method for visualising the data models.

\subsection{Process Deliverable Diagram}

The proposed solution is described in detail using the PDD (Weerd \& Brinkkemper, 2008; Proper, Bleeker \& Hoppenbrouwers, 2004), as it is shown in Figure 1. PDD makes activities and deliverables, explicit for the meta-process model of selected technique or method. The diagram is built as a collection of forms of activities (the process - derived from the UML activity diagram) and concepts (data as deliverables produced during the process derived from the UML class diagram). Concepts are linked as deliverable of the performed activity. Both concepts and activities are described in detail in Table 1 and Table 2.

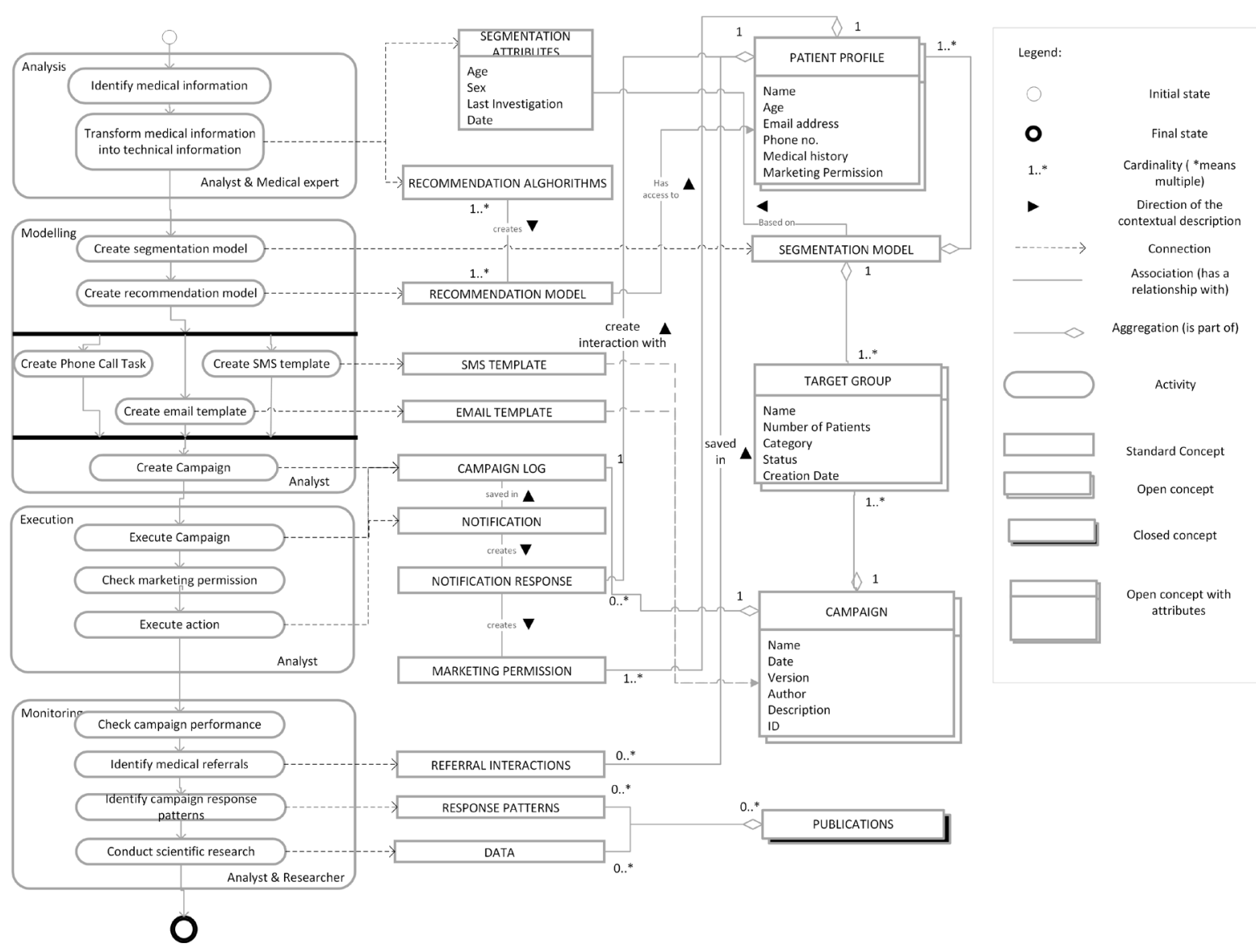

Figure 1. Process-deliverable diagram of blood analysis campaign execution (Adapted after Halpin, 1998) 
The process is modelled from the perspective of the healthcare provider which focuses on the patient well-being while following System Engineering Initiative for Patient Safety (SEIPS) framework in terms of data, processes and deliverables guidelines (Holden et al., 2013; Carayon et al., 2006). Activity diagram component presented in Figure 1 follows the SEIPS framework and the outcomes of the process according to this framework are represented by the deliverables connected through dashed lines.

The process of designing the PDD starts with the analysis phase involving the marketing analysts and the medical specialist. This phase is gathering the requirements and analysing the feasibility of a possible campaign. In the modelling phase, the marketing analyst creates in the system all necessary objects which are necessary to create the campaign. The next phase, named execution, triggers the action that involves the patient (email/ SMS message is sent out, task is created for the phone call if it is the case). The process ends with the monitoring phase that checks the results of the campaign, matches the possible referrals received as a result of the campaign execution and conducts a research based on the achieved results.

The proposed healthcare process modelled via a PDD in Figure 1 is seen as the usual marketing process for promoting a product (personalized blood test recommendation promotions) to customers (patients). The process starts when the marketing analyst agrees with the medical specialist on an algorithm that determines the recommendation for a group of patients. Further on, the analyst is transforming the medical information into technical information: particularities of patient groups called segmentation attributes and the algorithms needed

Table 1. Activity table of the modelled process in Figure 1

\begin{tabular}{|c|c|c|}
\hline Activity & Sub-Activity & Description \\
\hline \multirow{2}{*}{ Analysis } & Identify medical information & $\begin{array}{l}\text { Process starts with marketing analyst and medical expert that identify a possible } \\
\text { campaign (ex. General blood tests notification). }\end{array}$ \\
\hline & $\begin{array}{l}\text { Transform medical } \\
\text { information }\end{array}$ & $\begin{array}{l}\text { Medical information is corelated with data model identifying SEGMENTATION } \\
\text { ATTRIBUTES and RECOMMENDATION ALGHORITHMS }\end{array}$ \\
\hline \multirow{6}{*}{ Modelling } & Create Segmentation model & $\begin{array}{l}\text { The analyst is segmenting the data based on identified SEGMENTATION } \\
\text { ATTRIBUTES and creates a SEGMENTATION MODEL. Out of the } \\
\text { segmentation model, multiple TGs can be created. }\end{array}$ \\
\hline & $\begin{array}{l}\text { Create Recommendation } \\
\text { Model }\end{array}$ & $\begin{array}{l}\text { The analyst is creating RECOMMENDATION MODEL based on the } \\
\text { RECOMMENDATION ALGORITHM that fits to the patient data. }\end{array}$ \\
\hline & Create Phone Call Template & $\begin{array}{l}\text { PHONE CALL TEMPLATE is created with personalization attributes that will } \\
\text { be replaced when campaign is executed (runtime) with information related to } \\
\text { each TG member. }\end{array}$ \\
\hline & Create Email Template & $\begin{array}{l}\text { EMAIL TEMPLATE is created including personalization attributes that are } \\
\text { derived from the PATIENT PROFILE and RECOMMENDATION MODELS in } \\
\text { order to send personalized data to each target group member. }\end{array}$ \\
\hline & Create SMS Template & $\begin{array}{l}\text { SMS TEMPLATE is created by the analyst and includes personalization } \\
\text { attributes that will be replaced with TG member information at runtime. }\end{array}$ \\
\hline & Create Campaign & $\begin{array}{l}\text { The analyst models the campaign using the TARGET GROUP and the available } \\
\text { templates. Campaign automation includes all three communication channels } \\
\text { defined as action in order to ensure that based on their marketing permission } \\
\text { each TG member will receive a single personalized notification. }\end{array}$ \\
\hline \multirow{3}{*}{ Execution } & Execute Campaign & $\begin{array}{l}\text { CAMPAIGN status will be set to "Execute" and the system will send the } \\
\text { notifications to each TG member. }\end{array}$ \\
\hline & Check Marketing Permission & \multirow{2}{*}{$\begin{array}{l}\text { NOTIFICATIONs will be sent to each TG member according to his/her } \\
\text { permission. In case there are no permissions given no notification will be sent. }\end{array}$} \\
\hline & Execute action & \\
\hline \multirow{4}{*}{ Monitoring } & Check Campaign performance & $\begin{array}{l}\text { Campaign output will be checked in order to see if there are any errors, to } \\
\text { register how many NOTIFICATIONs have been send and if the campaign was } \\
\text { successful from a marketing perspective. }\end{array}$ \\
\hline & Identify medical referrals & \multirow{3}{*}{$\begin{array}{l}\text { MEDICAL REFERRAL obtained as outcome of the campaign will be linked } \\
\text { to the campaign. Based on the number of referrals a response pattern will } \\
\text { be determined (e.g. TG members that share particularity age }<50 \text { are } 80 \% \\
\text { responsive) and documented for further campaigns. In case of significant results } \\
\text { research can be published. }\end{array}$} \\
\hline & $\begin{array}{l}\text { Identify campaign response } \\
\text { patterns }\end{array}$ & \\
\hline & Conduct scientific research & \\
\hline
\end{tabular}

https://www.sic.ici.ro 
to determine the recommendation. Based on the identified segmentation attributes the analyst performs data segmentation thereby creating the target groups (e.g. TG containing all patients with gender $=$ male, age $>50$, last investigation date $>1$ year). A campaign for cancer screening is to be set up in the system, aiming to send a notification to all targeted customers containing a recommendation on blood tests personalized for each TG (e.g. Blood tests for Prostatic Specific Antigen). Notification templates will be created for all communication channels: email, SMS message and phone call. As soon as all elements are available the campaign is created. Once the campaign is executed, based on their marketing permission, TG members will receive a notification. In case the patients will follow the recommendation and a referral is registered in the system it will be linked to the campaign, being able to analyse its success. Based on the campaign results, patterns will be extracted that could be reused, improved and employed as a basis for scientific research.

Activity table of the modelled process is presented in Table 1 which includes both activities and sub-activities.

Table 2 explains the concepts used in Figure 1 from a functional perspective. The concepts are presented in a structured way that can be mapped to the technical objects needed in the implementation of a marketing system. 3 main objects are identified in the marketing process: patient profile, target group and campaign. Segmentation attributes are presented as a concept but from a technical perspective they act as properties/data attached to the patient profile object. 2 containers are presented as concepts: recommendation (technical objects: recommendation algorithms and models) and content studio (technical objects: email and SMS templates).

Table 2. Detailed explanations of the concepts peculiar to the modelled process in Figure 1

\begin{tabular}{|c|c|}
\hline Concept & Description \\
\hline Patient profile & $\begin{array}{l}\text { PATIENT PROFILE provides a unique view of the patient personal data, interactions (all actions } \\
\text { registered in the system e.g. referrals, analysis, appointments, notifications sent, etc.) and marketing } \\
\text { permissions. }\end{array}$ \\
\hline $\begin{array}{l}\text { Segmentation } \\
\text { Attributes }\end{array}$ & $\begin{array}{l}\text { SEGMENTATION ATTRIBUTES are common attributes maintained in the patient profile that are used } \\
\text { in segmentation in order to group the patients such as age, gender, occupation, education, geographical } \\
\text { variables (urban vs rural), last investigation date, etc. }\end{array}$ \\
\hline Segmentation Model & $\begin{array}{l}\text { SEGMENTATION MODEL is used to group patients based on SEGMENTATION ATTRIBUTES. } \\
\text { Segmentation model can generate on or more target groups based on the combination of segmentation } \\
\text { attributes used in the model. }\end{array}$ \\
\hline Target Group & $\begin{array}{l}\text { TARGET GROUP is a set of patients categorized according to certain criteria (segmentation } \\
\text { attributes). The concept is identifying according to the number of members, a name, category (static= } \\
\text { fix number of members, dynamic = variable number of members calculated at different moments in } \\
\text { time based on a trigger). }\end{array}$ \\
\hline $\begin{array}{l}\text { Recommendation } \\
\text { Algorithm/ } \\
\text { Recommendation } \\
\text { Model }\end{array}$ & $\begin{array}{l}\text { RECOMMENDATION is a collection of algorithms that are used for creating recommendation models } \\
\text { with the aim of providing patients with relevant recommendations in real time. Data scientists create } \\
\text { algorithms to query the database and retrieve recommendations based on historical data stored in the } \\
\text { patient profile or in the medical database. E. g. Patient A will receive recommendation to perform blood } \\
\text { test } \mathrm{X} \text { based on his/her historical data and based on the historical data of other patients. }\end{array}$ \\
\hline $\begin{array}{l}\text { SMS template/Email } \\
\text { template }\end{array}$ & $\begin{array}{l}\text { SMS TEMPLATE and EMAIL TEMPLATES are a collection of marketing content (emails and text } \\
\text { messages). Those objects can be reused in multiple campaigns depending on the personalization level. }\end{array}$ \\
\hline Campaign & $\begin{array}{l}\text { A CAMPAIGN is a container used for various activities focussed on patients that have been } \\
\text { categorized in a target group having as outcome an action that involves TG members. Campaign acts } \\
\text { as final diagram in the PPD diagram presented in Figure } 1 .\end{array}$ \\
\hline Campaign Log & CAMPAIGN LOG is a collection of statuses and logs of the campaign object. \\
\hline $\begin{array}{l}\text { Notification/ } \\
\text { Notification response/ } \\
\text { Referral Interactions }\end{array}$ & $\begin{array}{l}\text { NOTIFICATION represents the outcome of the actions set in the campaign automation that interfere } \\
\text { with the patient (email, SMS, phone call, letter). Any feedback received from the patient is considered } \\
\text { NOTIFICATION RESPONSE and is logged to his/her profile. A notification response can be a } \\
\text { REFERRAL INTERACTION or a request for changing the patient MARKETING PERMISSION. }\end{array}$ \\
\hline Response Patterns & $\begin{array}{l}\text { RESPONSE PATTERNS are the outcome of marketing campaign results being translated, if relevant, } \\
\text { into response patterns in terms of TG members availability, notification response, etc. }\end{array}$ \\
\hline Publications/ Data & $\begin{array}{l}\text { A PUBLICATION is a published paper based on the DATA extracted from the scientific research } \\
\text { resulting from the monitoring of campaign execution. }\end{array}$ \\
\hline
\end{tabular}




\subsection{Unified Patient Profile - Data Model}

Marketing systems are designed to store all patient information relevant for marketing processes: personal data, data origin, marketing permission and interactions (technical name for actions performed by the patient or for the patient).

\subsection{Marketing Permissions}

Marketing permissions are regulated in Europe via General Data Protection regulation (GDPR) (EUR-Lex, 2016) and in the United States via Health Insurance Portability and Accountability Act (HIPAA) (U.S. Department of Health and Human Services, 2020).

CRM technology implemented in all major systems can reach targeted consumers through all available communication channels (email, phone, social media, paper, etc.) following all present legal regulations for each geographical region as standard functionality.

This paper focuses on the EU regulations (GDPR). According to these regulations, any individual needs to have control over his/her personal data. Current healthcare design is considering these regulations in terms of marketing permission technical object. Permissions are stored in the database and are part of the data model for patient profile and consider the communication channel (email, phone, SMS, paper, etc.) and opt in/ opt out as values.

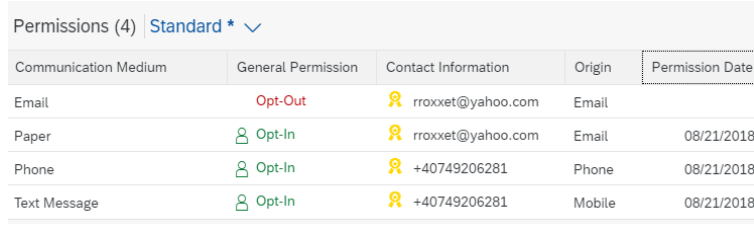

Figure 2. Marketing permission visualization in the patient profile - data model

\subsection{Segmentation}

According to (Chong, Lim \& Matchar, 2019), that presents a review of segmentation in the literature, consisting in 9970 articles a total number of 16 unique tools are identified to be used in healthcare segmentation producing a variable number of segments. Both data and expert-driven types are presented along with their base types that is medical, demographic, functional, etc.
Segmentation algorithms are not within the scope of this paper, which focuses on the endto-end marketing process that involves patient segmentation in order to set up a campaign.

The importance of market segmentation studies and their benefits in healthcare, addressing different dimensions of data mining applications in healthcare, are discussed in detail in literature (Marcu, Popescu \& Danila, 2020), (Eric et al., 2018). (Islam et al., 2018) presents the perspective of expanding patient data by using advanced data mining methods. (Kringos et al., 2014) review market segmentation research and emphasize the potential benefits of preventive care. In addition, the lack of research in the area of medical processes implemented by healthcare providers have been highlighted.

\subsection{Recommendation}

Recommendation algorithms are extracting data based on standard queries on data using patient profile data model or target groups. For example, a patient that has been included in a TG using a series of segmentation attributes (age, gender, historical data) where all the other members have a referral for a certain blood test attached to their profiles will be identified as a match. The match means that the patient condition is relevant for the same referral and a notification can be sent.

Recommendation algorithms are grouped into recommendation models in case a more complex logic is required (translated into database queries).

\subsection{Campaign Execution}

A campaign is a container used for various activities focused on patients, potential patients or contact persons that have been categorized in a target group. Campaign object contains validity period, information about the used target groups, triggers and actions and information about its execution.

Figure 3 illustrates the campaign setup process performed in a marketing system according to the PPD diagram presented in Figure 1. A target group is selected to be notified by an email, SMS message or phone call task based on the data peculiar to each target group member. In case an

https://www.sic.ici.ro 


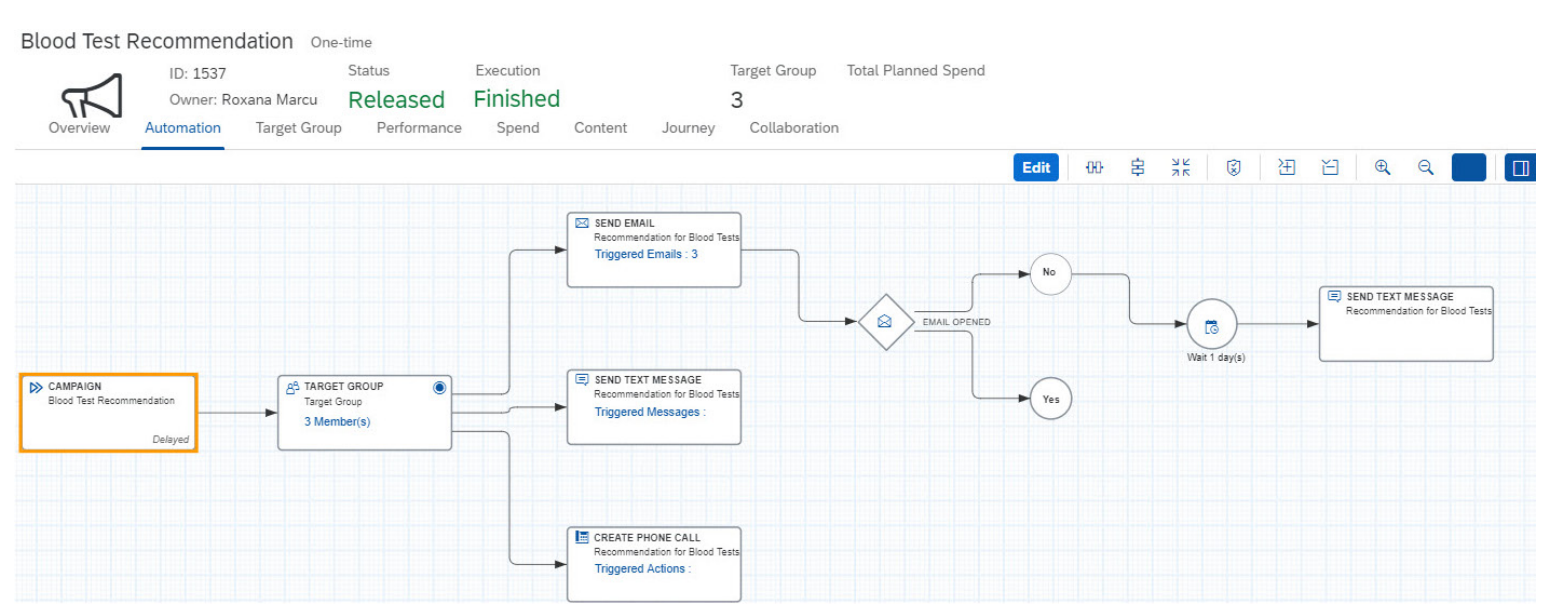

Figure 3. Campaign modelling in a marketing system according to the PPD diagram presented in Figure 1

email has been sent but not opened in a certain time interval a SMS message will be sent to the same TG member.

Figure 4 shows how the marketing permission is considered for the campaign illustrated in Figure 3. Amoung 3 TG members only one email has been sent out. 2 emails failed to be delivered due to marketing permission saved in the contact profile.

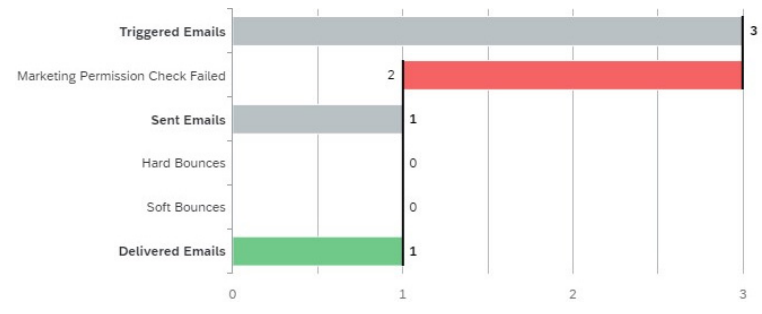

Figure 4. Marketing permission check for the campaign execution presented in Figure 3

\section{Conclusion}

Healthcare IT systems are complex in terms of implementation process, aiming to support safe and high-quality patient care. Required business processes are challenging from the perspective of flow complexity, data privacy regulations, deliverables and actors involved in the process. Due to the lack of researches in the area of medical prevention implementation, this paper proposes a designing and modelling solution for visualizing healthcare processes through a meta-modelling technique studied in detail in (EUR-Lex, 2016; Halpin, 1998) a designing and modelling solution for visualizing healthcare processes.
An example of marketing segmentation and campaign execution in healthcare has been proposed as a solution of reusing standard CRM processes in the preventive medicine. Blood tests notifications for cancer screening are sent to the targeted patients. The referrals are indexed for future research and marketing analysis. The example is presented via a PPD diagram aiming to explain what activities are conducted and by what actors, what deliverables are produced and stored in the system as a result of the conducted activities including the relationships between the deliverables.

This research aims to present a theoretical perspective on a complex healthcare information system implementation. Limitations have been identified for the proposed solution in terms of real mapping with system technical objects. The proposed process is subject to review, refinement and validation via a real case study.

As future research the authors propose to run a campaign on a real TG with the use of a medical provider and analyse the response of the campaign. The proposed visualization technique is planned to be extended with additional medical processes and develop recommendation algorithms for the identifications of TG members.

\section{Acknowledgements}

This work has been funded through the Operational Programme "Human Capital" of the Ministry of European Funds based on the Financial Agreement 51675/09.07.2019, SMIS code 125125 . 


\section{REFERENCES}

Baashar, Y. M., Mahomood, A. K., Almomani, M. A. \& Alkawsi, G. A. (2016). Customer Relationship Management (CRM) in Healthcare Organization: A Review of Ten Years of Research. In 3rd International Conference on Computer and Information Sciences (ICCOINS), (pp. 3-4).

Blijleven, V., Jaspers, M., Wetzels, M., Koelemeijer, K., Mehrsai, A. (2016). A Meta-Modelling Technique for Analysing, Designing and Adapting Healthcare Processes: A Process-Deliverable Perspective. In IEEE-EMBS International Conference on Biomedical and Health Informatics (BHI), Las Vegas, NV (pp. 316-319). DOI: 10.1109/BHI.2016.7455898

Carayon, P., Hundt, A., Karsh, B., Gurses, A., Alvarado, C., Smith, M. \& Brennan, P. F. (2006). Work system design for patient safety: the SEIPS model, Quality and Safety in Health Care, 15 Suppl 1(Supplement I), i50-i58.

Ceresoli, J. D. \& Kuhl, M. E. (2018). A simulation framework for the design and analysis of healthcare clinics. In Proceedings of the 2018 Winter Simulation Conference (pp. 213-220).

Chong, J. L., Lim, K. K. \& Matchar, D. B. (2019). Population segmentation based on healthcare needs: a systematic review, Systematic Reviews, 8, 202.

EUR-Lex (2016). Access to European Union Law, Law 2016/679. Available at: $<$ https://eur-lex.europa.eu/legal-content/EN/ $A L L /$ ? uri $=$ CELEX\%3A32016R0679>, last accessed: 10 January 2020.

Halpin, T. (1998). Object-Role Modelling (ORM/ NIAM), Handbook on Architectures of Information Systems Object-Role Modelling (ORM/NIAM), 81105. Heidelberg: Springer.

Holden, R. J., Carayon, P., Gurses, A. P., Hoonakker, P., Hundt,A. S., Ozok, A.A. \& Rivera-Rodriguez, A. J. (2013). SEIPS 2.0: A human factors framework for studying and improving the work of healthcare professionals and patients, Ergonomics, 56(11), 1669-1686.

Islam, S., Hasan, M., Wang, X., Germack, H. D. \& Alam, N. (2018). A Systematic Review on Healthcare Analytics: Application and Theoretical Perspective of Data Mining, MDPI Healthcare Journal, 6(2), 5-10.

Jean-Baptiste, D., O’Malley, A. S. \& Shah, T. (2017). Population Segmentation and Targeting of Health Care Resources: Findings from a Literature Review, Working Paper 58, 2-6. Washington, DC: Mathematica Policy Research.

Jones, S., Rees, L., Hall, D. \& Tang, A. (2005). Using market segmentation theory to select target markets for sun protection campaigns. In Purchase, S. (ed.), Proceedings of the ANZMAC Conference, University of Western Australia (pp. 144-148).
Kringos, D. S., Aryankhesal, A., Manouchehri J. \& Klazinga, N. (2014). Development and impact of the Iranian hospital performance measurement program, BMC Health Services Research, 14(1), 448. DOI: 10.1186/1472-6963-14-448

Marcu, R. \& Popescu, D. (2015). Security solution for healthcare hybrid cloud platform. In International Conference on System Theory, Control and Computing (pp. 3-4).

Marcu, R., Popescu, D. \& Danila, I. (2020). Optimize recommendation Engine for Marketing System in Healthcare CRM. In $12^{\text {th }}$ International Conference on Electronics, Computers and Artificial Intelligence ECAI (pp. 4-6).

Proper, H. A., Bleeker, A. I. \& Hoppenbrouwers, S. J. B. A. (2004). Object-role modelling as a domain modelling approach. In Proceedings of the $16^{\text {th }}$ Conference on Advanced Information Systems (CAiSE) Workshops (pp. 317-328).

Radu, G., Solomon, M., Gheorghe, C. M., Hostiuc, M., Bulescu, I. A. \& Purcarea, V. L. (2017). The adaptation of healthcare marketing to the digital era, Journal of Medicine and Life, 10(1), 44-46.

ReportsnReports (2018). Healthcare CRM Market by Component (Software, Service), Delivery (On premise, Cloud, Public, Private, Hybrid), End user (Hospital, ASC, Payers, Life Science), Functionality (CSS, Marketing, Sales, Digital Marketing, AI, Analytics) - Global Forecast to 2023. Available at: $\quad<$ https://www.marketsandmarkets.com/MarketReports/healthcare-crm-market-88873203.html>, last accessed: 26 August 2020.

Swenson, E., Bastian, N. \& Nembhard, H. (2018). Healthcare market segmentation and data mining: A systematic review, Health Marketing Quarterly, 35(3), 6-21. DOI: 10.1080/07359683.2018.1514734

Torpie, K. (2014). Customer service vs. Patient care, Patient Experience Journal, 1(2), 7-8.

U.S. Department of Health and Human Services. (2020). Health Information Privacy Official Website. Available at: <https://www.hhs.gov/hipaa/forindividuals/guidance-materials-for-consumers/index. html>, last accessed: 15 January 2020.

Weerd, I. \& Brinkkemper, S. (2008) Meta-modelling for situational analysis and design methods. In Syed, M. R. \& Syed, S. N. (eds.), Handbook of Research on Modern Systems Analysis and Design Technologies and Applications, 38-58.

WHO (2016). Long-term trends in mortality: implications for developing countries. Available at: $<$ www.who.int $>$, last accessed: 26 August 2020. 